\title{
Development Assessment of Higher Education System Based on TOPSIS-Entropy, Hopfield Neural Network, and Cobweb Model
}

\author{
Xian-Bei Liu $\mathbb{D}$, ${ }^{1,2}$ Yu-Jing Zhang $\mathbb{D},{ }^{3}$ Wen-Kai Cui $\mathbb{D}^{,},{ }^{3}$ Li-Ting Wang $\mathbb{D}{ }^{4}$, \\ and Jia-Ming Zhu $\mathbb{D}^{1,5}$ \\ ${ }^{1}$ School of Statistics and Applied Mathematics, Anhui University of Finance and Economics, Bengbu 233030, China \\ ${ }^{2}$ School of Business, University of Perpetual Help System Dalta, Las Piñas 1740, Philippines \\ ${ }^{3}$ Institute of Finance, Anhui University of Finance and Economics, Bengbu 233030, China \\ ${ }^{4}$ School of Accounting, Anhui University of Finance and Economics, Bengbu 233030, China \\ ${ }^{5}$ Institute of Quantitative Economics, Anhui University of Finance and Economics, Bengbu 233030, China \\ Correspondence should be addressed to Jia-Ming Zhu; zhujm1973@163.com
}

Received 23 February 2021; Revised 12 March 2021; Accepted 15 March 2021; Published 25 March 2021

Academic Editor: Shaohui Wang

Copyright $\odot 2021$ Xian-Bei Liu et al. This is an open access article distributed under the Creative Commons Attribution License, which permits unrestricted use, distribution, and reproduction in any medium, provided the original work is properly cited.

\begin{abstract}
This paper first extracted 11 indicators from four aspects of infrastructure, educational equity, teaching quality, and scientific research level and established a multidimensional higher education evaluation system. After that, according to TOPSIS and the entropy method, a comprehensive score of the development of higher education was obtained, and a comprehensive index of higher education was proposed. According to the level of the score, we divide the development status into 5 categories, and use discrete Hopfield neural network for verification. In addition, we applied the model to many countries and chose Vietnam to conduct an in-depth analysis of the model, including reforming policies and evaluating policy effects based on cobweb model. Finally, we found that the application of the model is very universal, but in reality the reform is very difficult.
\end{abstract}

\section{Introduction}

With the development of countries in the world, the higher education system is gradually improving. At the same time, the competition for talents has intensified. Having a healthy, sustainable higher education system means that more local talents can be cultivated and international talents can be attracted [1]. Therefore, how to make a reasonable evaluation of a country's higher education system has become the focus of attention of educators and policy makers in various countries.

Appropriate multidimensional evaluation of a country's higher education system, on the one hand, can effectively reflect the local education level and civic literacy through data indicators; on the other hand, it can quantify the educational differences between countries in the world, which is beneficial to talents flow and reformations of the education system in underdeveloped areas [2]. Due to the abovementioned various reasons, the establishment of a comprehensive and universal higher education evaluation index system is essential to the modernization of higher education and the current social development [3].

Due to differences in cultural traditions and social systems, the current higher education evaluation systems in different countries in the world are not the same [4-8]. In the study of evaluation methods, most scholars choose a combination of qualitative and quantitative methods [9-12] to evaluate the development level of higher education and have achieved good research results in the evaluation of development status and the carrying capacity of educational resources $[13,14]$.

In the research of higher education system evaluation, early scholars mainly focused on the construction of the index system [15-17], and there was little research on the application of models and the effectiveness of reforms. Therefore, after constructing a multidimensional and comprehensive higher education evaluation system, this paper also discusses in detail the application of realistic 
species and the evaluation of policy effects. It mainly includes the following aspects: (i) use relevant data to establish a set of models to evaluate the health of a country's higher education system and verify this model. (ii) Apply the model to countries with room for improvement, propose targeted reform measures, and measure the health of the proposed, healthy, and sustainable system. (iii) Use economic models to discuss the obstacles to reform in reality, and discuss whether it is possible to change the poor and weak status of higher education development in underdeveloped regions. The general idea is shown in Figure 1.

\section{Basic Assumptions}

In order to solve the problem, we make assumptions as follows: (i) assume that the data consulted are true and reliable; (ii) assume that the model does not consider the impact of wars and plagues on higher education; (iii) assume that the model does not consider the influence of personal factors such as educational preferences on higher education; (iv) assume that the future economy of the country where the model is applied will grow steadily in order to ensure uninterrupted implementation of reform policies; (v) assume that the expenditure of education funds has a time lag on the higher education system and will not immediately have a significant impact on the current period.

\section{How to Evaluate the Development of a Country's Higher Education System and Quantify Its Comprehensive Results?}

3.1. Analysis Approach. Although both analytic hierarchy process and TOPSIS can evaluate a series of individuals, the analytic hierarchy process is only applicable when there are no clear quantitative indicators, and it is not objective and rigorous. Compared with many limitations of the analysis hierarchy process, the TOPSIS method usually has clearly quantified decision variables that can be evaluated and ranked based on existing data. However, the TOPSIS method cannot obtain objective weights, so the entropy weight method is introduced. Entropy method construction coefficients use the knowledge of information theory. The greater the degree of variation (variance) of the data, the greater the amount of information contained in this indicator, and the more important it is. Since the entropy weight method has the advantage of overcoming the subjectivity of the subjective weighting method, the entropy weight method can be used to objectively and accurately evaluate the research object. Therefore, we combine TOPSIS and the entropy method to establish a multidimensional and comprehensive evaluation model for the development of higher education $[18,19]$.

On the basis of the existing research results, in order to comprehensively and deeply study the influencing factors of a country's higher education system, we build a multidimensional comprehensive evaluation system of the healthy development of the higher education system from the four perspectives of infrastructure, educational equity, teaching quality, and scientific research level.

\subsection{Evaluation System of Higher Education Based on TOPSIS and Entropy Weight Method}

3.2.1. Model Preparation. Considering the factors affecting the healthy development of higher education, a multilevel evaluation structure should be established to evaluate higher education. We mainly analyze four aspects of infrastructure, educational equity, teaching quality, and scientific research level. Each aspect corresponds to several specific indicators, as shown in Table 1.

After establishing the indicator system, we obtained relevant data on higher education systems in 20 countries from the official website of the World Bank. Since the original data are large and incomplete, it is necessary to preprocess the data. The specific steps are as follows:

(i) Step 1. Data screening: the original data have the problem of missing and redundant, so we first delete null values and unreadable data.

(ii) Step 2. Supplement of missing data: we use the BP neural network to collect data by training and constantly modifying weights and thresholds [20]. The missing data in the data were supplemented.

(iii) Step 3. Data normalization and data standardization:

For positive indicators,

$$
x_{i j}=\frac{x_{i j}-\min \left(x_{i j}\right)}{\max \left(x_{i j}\right)-\min \left(x_{i j}\right)} .
$$

For contrarian indicators,

$$
x_{i j}=\frac{\max \left(x_{i j}\right)-x_{i j}}{\max \left(x_{i j}\right)-\min \left(x_{i j}\right)} .
$$

For intermediate indicators,

$$
x_{i j}=1-\frac{\left|x_{i j}-x_{\text {best }}\right|}{\max \left(\left|x_{i j}-x_{\text {best }}\right|\right)} .
$$

The indicator data values are uniformly transformed into the $[0,1]$ interval. The model uses linear transformation method to standardize the index data. Among them, $x_{i j}$ is the standardized index. In the higher education evaluation system, $x_{i j}$ represents the actual value of the sample data of the $j$-th indicator of the $i$-th country.

3.2.2. Model Establishing and Solving. There are several steps in the process of establishing TOPSIS and the entropy weight model. We first use the entropy method to calculate the weight of each indicator, and we calculate the relative proportion $P_{i j}$ of the index for the health of higher education development in the $i$-th country under the $j$-th index. The formula is 


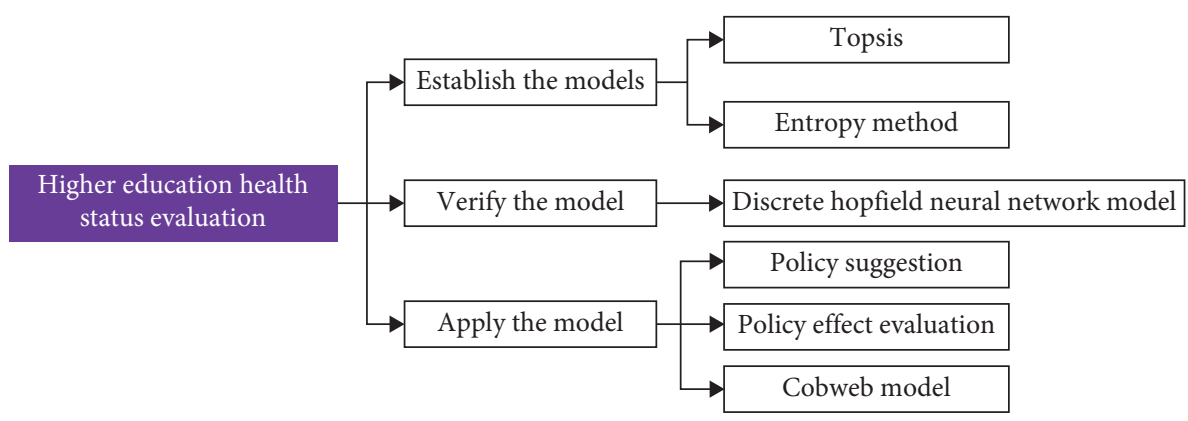

FIgURE 1: Overall thinking process.

TABLE 1: Hierarchy table.

\begin{tabular}{|c|c|c|c|}
\hline Target layer & Level 1 criterion layer & Level 2 program layer & Mark \\
\hline \multirow{4}{*}{ Higher education } & Infrastructure factors & $\begin{array}{l}\text { Number of institutions of higher learning } \\
\text { Number of teachers in institutions of higher learning }\end{array}$ & $\begin{array}{l}X_{1} \\
X_{2}\end{array}$ \\
\hline & \multirow{3}{*}{ Educational equity factors } & Gender ratio of college students & $X_{3}$ \\
\hline & & Share of teachers between private and public universities & $X_{4}$ \\
\hline & & Higher education enrollment rate & $X_{5}$ \\
\hline \multirow{6}{*}{ Health evaluation } & \multirow{3}{*}{ Teaching quality factors } & Graduate quality & $X_{6}$ \\
\hline & & Postgraduate rate & $X_{7}$ \\
\hline & & Government expenditure on higher education ( $\%$ of GDP) & $X_{8}$ \\
\hline & \multirow{3}{*}{ Scientific research level factors } & Number of scientific researchers (per million people) & $X_{9}^{\circ}$ \\
\hline & & Number of high-quality scientific research articles output & $X_{10}$ \\
\hline & & Scientific research expenditure (\% of GDP) & $X_{11}$ \\
\hline
\end{tabular}

$$
p_{i j}=\frac{x_{i j}}{\sum_{i=1}^{n} x_{i j}} .
$$

We can get the normalized matrix $P$ of the original matrix, which is

$$
\left(P_{i j}\right)_{m \times n}=\left[\begin{array}{cccc}
P_{11} & P_{12} & \cdots & P_{1 n} \\
P_{21} & P_{22} & \cdots & P_{2 n} \\
\cdots & \cdots & \cdots & \cdots \\
P_{m 1} & P_{m 2} & \cdots & P_{m n}
\end{array}\right] .
$$

Then, we calculate the entropy of each indicator $X_{j}$. According to the formula,

$$
e_{j}=-k \sum_{i=1}^{n} p_{i j} \ln \left(p_{i j}\right) \text {. }
$$

Among them, $k=1 / \ln n>0,0 \leq e_{j} \leq 1$, if $x_{i j}$ is all equal to the specified index $j$, then let $p_{i j}=1 / n$, and at this time, $e_{j}=k \ln n$.

After obtaining the entropy value, we calculate the degree of difference (information utility value) of each indicator and set the difference coefficient as $g_{j}$. The formula we define the coefficient of difference is $g_{j}=1-e_{j}$. The larger the $g_{j}$, the more the indicator needs to be paid attention to. From this formula, we can see that the smaller $g_{j}$ is, the larger $e_{j}$ is. When $g_{j}$ are all equal, $e_{j}$ reaches the maximum value, and the maximum value is 1 . At this time, the size of the index will not have any influence on the evaluation result, so this indicator has no effect. When the difference between the indicators is larger, the $e_{j}$ is smaller, which means that this indicator has a stronger effect on evaluating the development of higher education.

Based on this, we can calculate the weight of each indicator:

$$
w_{j}=\frac{g_{j}}{\sum_{j=1}^{n} g_{j}} .
$$

The corresponding entropy weight matrix is

$$
X=\left[\begin{array}{cccc}
X_{1} & 0 & \cdots & 0 \\
0 & X_{2} & \cdots & 0 \\
\cdots & \cdots & \cdots & \cdots \\
0 & 0 & \cdots & X_{n}
\end{array}\right] .
$$

Due to the different importance of each index, entropy weight should be considered. The weighted normalized matrix can be obtained by multiplying the index weight $w_{j}$ and normalized matrix.

Then, we calculate the positive and negative ideal solution. We use $y_{j}^{+}$to represent the maximum value of the $k$ th index observation data and $y_{j}^{-}$to represent the minimum value of the $k$-th index observation data, which is expressed as $y_{j}^{+}=\max _{1 \leq i \leq m}\left(r_{i j}\right), y_{j}^{-}=\min _{1 \leq i \leq m}\left(r_{i j}\right)$. Therefore, the positive ideal solution of the evaluation scheme is $y_{j}^{+}=\left(y_{1}^{+}, y_{2}^{+}, \cdots y_{m}^{+}\right)$, and the negative ideal solution is $y_{j}^{-}=\left(y_{1}^{-}, y_{2}^{-}, \cdots y_{m}^{-}\right)$.

After that, we calculate the distance between the index and the positive and negative ideal solutions. Let $d_{i}^{+}$be the 
distance between the $i$-th index and the positive ideal solution. Let $d_{i}^{-}$be the distance between the $i$-th index and the negative ideal solution:

$$
\begin{aligned}
& d_{i}^{+}=\sqrt{\left(y_{1}^{+}-y_{1 i}\right)^{2}+\cdots+\left(y_{m}^{+}-y_{m i}\right)^{2}}, \\
& d_{i}^{-}=\sqrt{\left(y_{1}^{-}-y_{1 i}\right)^{2}+\cdots+\left(y_{m}^{-}-y_{m i}\right)^{2}} .
\end{aligned}
$$

Finally, we calculate the result of relative closeness. Let $c_{i}$ be the relative closeness of the $j$-th index of the $i$-th country to the ideal solution:

$$
c_{i}=\frac{d_{i}^{-}}{d_{i}^{+}+d_{i}^{-}} .
$$

The larger the value of $c_{i}$, the closer the decision is to the positive ideal solution, and the better the development of higher education of the evaluation object. The order of relative closeness is the order of the development status of higher education in various countries.

3.3. Result Analysis. According to the above steps to calculate the collected data, and using the mathematical software MATLAB calculation, we can obtain the entropy and weight of each secondary index, which will be used for the calculation of the comprehensive score later. The results are shown in Table 2.

After getting the weight and entropy, we multiply it with the standard matrix, combine the distance with the positive and negative ideal solution, determine the relative proximity, and finally get the comprehensive score of the development of higher education in various countries, which we call the higher education comprehensive index (HECI).

According to the scoring results, we divided the development status of higher education into five levels: very healthy, healthy, fair, poor, and poor. Each grade and its corresponding score are shown in Table 3.

The scores of higher education in 20 countries and their grading results are shown in Table 4 .

We use histogram and radar chart to show the score results, as shown in Figures 2 and 3. In the histogram of Figure 2, the darker areas indicate that the country has a higher comprehensive index of higher education and a healthy development status. In the radar chart of Figure 3, the high-ranking countries have high evaluation scores and good development status.

\section{Classification and Recognition of Higher Education Development Based on Discrete Hopfield Neural Network Model}

4.1. Analysis Approach. In the evaluation of a country's higher education system by the TOPSIS-entropy method, we proposed five classifications. In order to verify the objectivity of the model and the accuracy of classification, we learned from dynamics knowledge and designed a discrete Hopfield neural network model. The discrete Hopfield neural network model simulates the evolution of neurons in the direction of energy reduction and establishes a self-feedback model, which can effectively verify the model classification [21]. The schematic diagram of the neural network is shown in Figure 4.

4.2. Model Establishing and Solving. First, we design the ideal performance evaluation index and regard the average value of each evaluation index corresponding to the samples of each level is regarded as the ideal evaluation index of each level, that is, as the balance point of the Hopfield neural network.

Secondly, we divide the ideal grade indicator code according to the data. Since the states of discrete Hopfield neural network neurons are only 1 and -1 , when the evaluation index is mapped to neurons, it needs to be coded. We design the coding rule as follows: when the index is greater than or equal to a certain level, the corresponding neuron state is set to 1 ; otherwise, it is set to -1 . When the image is represented, a color-labeled neuron is used to indicate greater than or equal to a certain level, and we use white neurons to indicate indicators less than a certain level.

For a binary neuron, its calculation formula is as follows:

$$
u_{j}=\sum_{i} w_{i j} y_{i}+x_{j}
$$

In the formula, $x_{j}$ is the external input, and there is

$$
\begin{cases}y_{j}=1, & u_{j} \geq \theta_{j}, \\ y_{j}=-1, & u_{j}<\theta_{j} .\end{cases}
$$

The network state of a discrete Hopfield neural network is a collection of output neuron information. For a network with $n$ neurons in the output layer, the state at time $t$ is an $n$ dimensional vector:

$$
Y(t)=\left[y_{1}(t), y_{2}(t), \ldots, y_{n}(t)\right]^{T} .
$$

We use $y_{j}(t)$ to represent the $j$-th neuron, that is, the state of node $j$ at time $t$, and the state of the node at the next time $(t+1)$ can be obtained by the following formula:

$$
\begin{gathered}
y_{j}(t+1)=f\left[u_{j}(t)\right]= \begin{cases}1, & u_{j}(t) \geq 0 \\
-1, & u_{j}(t)<0 .\end{cases} \\
u_{j}(t)=\sum_{i} w_{i j} y_{i}(t)+x_{j}-\theta_{j} .
\end{gathered}
$$

Finally, we conduct classification verification of the model. In order to test the objective and fairness of the classification result, we randomly select 5 countries for evaluation in different higher education ratings. These 5 countries are the United States, China, France, Vietnam, and Somalia. After that, we create a Hopfield neural network to get the simulation result.

4.3. Result Analysis. The simulation results are shown in Figure 5. The first line represents the five ideal performance evaluation index codes to be evaluated, which are very healthy, healthy, general, poor, and very poor. The second 
TABLE 2: Comprehensive evaluation results obtained by TOPSIS and the entropy weight method.

\begin{tabular}{|c|c|c|c|}
\hline First level indicators & Secondary indicators & Weight & Entropy \\
\hline \multirow{2}{*}{ Infrastructure factors } & Number of institutions of higher learning & 0.075 & 0.95 \\
\hline & Number of teachers in institutions of higher learning & 0.22 & 0.86 \\
\hline \multirow{3}{*}{ Educational equity factors } & Gender ratio of college students & 0.27 & 0.83 \\
\hline & Share of teachers between private and public universities & 0.06 & 0.96 \\
\hline & Higher education enrollment rate & 0.11 & 0.93 \\
\hline \multirow{3}{*}{ Teaching quality factors } & Graduate quality & 0.06 & 0.96 \\
\hline & Postgraduate rate & 0.07 & 0.95 \\
\hline & Government expenditure on higher education (\% of GDP) & 0.06 & 0.96 \\
\hline \multirow{3}{*}{ Scientific research level factors } & Number of scientific researchers (per million people) & 0.06 & 0.96 \\
\hline & Number of high-quality scientific research articles output & 0.06 & 0.96 \\
\hline & Scientific research expenditure (\% of GDP) & 0.06 & 0.96 \\
\hline
\end{tabular}

TABLE 3: Rating level.

\begin{tabular}{lccccc}
\hline Comprehensive score & $0-45$ & $45-60$ & $60-75$ & $75-90$ & $90-100$ \\
\hline Higher education grades & Very poor & Poor & General & Healthy & Very healthy \\
\hline
\end{tabular}

TABle 4: Comprehensive score sheet.

\begin{tabular}{lccc}
\hline Rank & Countries & HECI & Grades \\
\hline 1 & USA & 98.01 & Very healthy \\
2 & Canada & 95.97 & Very healthy \\
3 & Japan & 93.14 & Very healthy \\
4 & Britain & 93.14 & Very healthy \\
5 & Germany & 87.77 & Healthy \\
6 & Singapore & 84.95 & Healthy \\
7 & China & 82.12 & Healthy \\
8 & Australia & 79.45 & Healthy \\
9 & Netherlands & 76.89 & Healthy \\
10 & South Korea & 71.25 & General \\
11 & New Zealand & 68.52 & General \\
12 & France & 64.67 & General \\
13 & Sweden & 61.22 & General \\
14 & Brazil & 60.90 & General \\
15 & India & 57.12 & Poor \\
16 & Vietnam & 49.82 & Poor \\
17 & Indonesia & 43.56 & Very poor \\
18 & Poland & 30.42 & Very poor \\
19 & Egypt & 15.15 & Very poor \\
20 & Somalia & 3.9 & Very poor \\
\hline
\end{tabular}

line represents the five national higher education system evaluation index codes to be classified, and the third line represents the result of the Hopfield neural network classification. It can be clearly seen from the figure that the designed Hopfield network can effectively classify, so as to make an objective and fair evaluation of the health of a country's higher education system.

The simulation results show that the higher education system rating in the United States is very healthy, the higher education system rating in China is relatively healthy, the higher education system rating in France is general, the higher education system rating in Vietnam is poor, and the higher education system rating in Somalia is very poor, which is consistent with the above results. This confirms the accuracy of the TOPSIS-entropy weight method and higher education system classification, as well as the objective and reasonable division of the classification index.

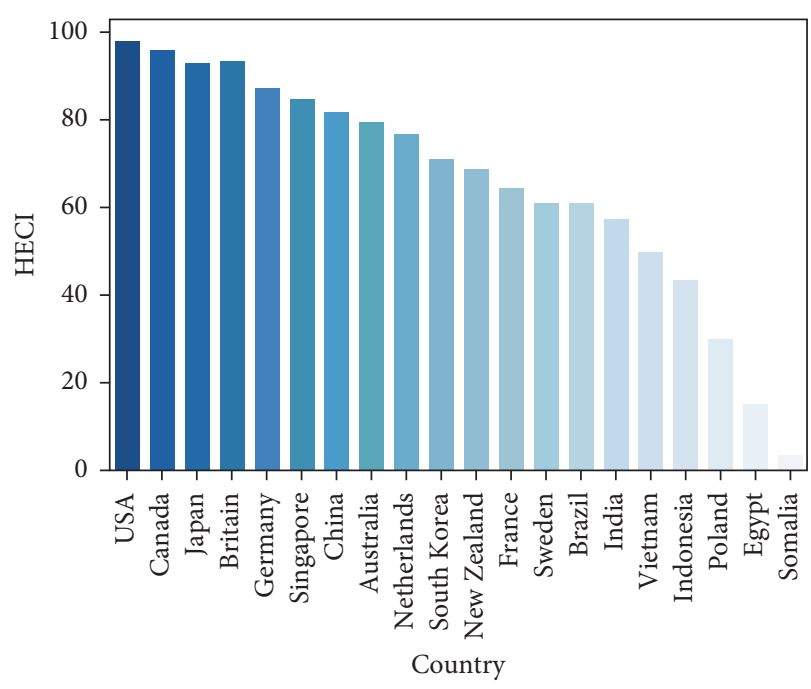

FIgURE 2: Comprehensive score histogram.

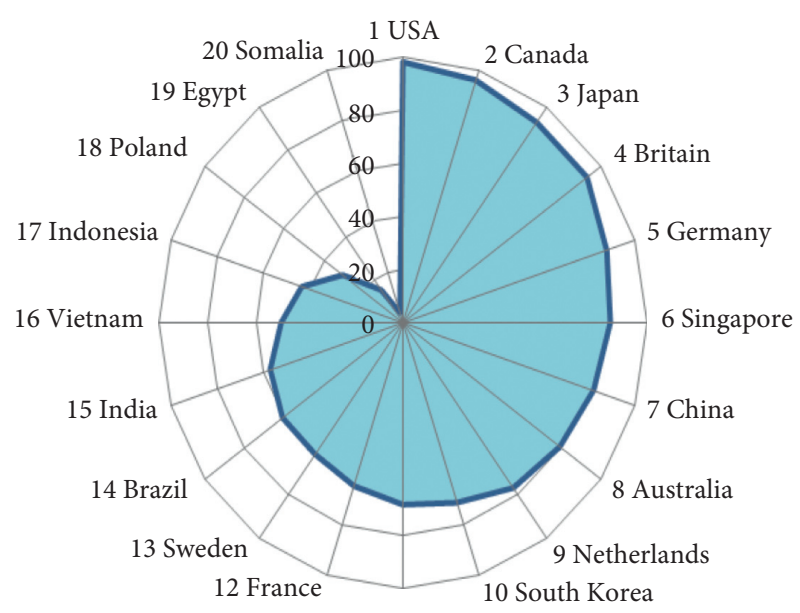

11 New Zealand

Overall ratings

FIgURE 3: Comprehensive score radar chart. 


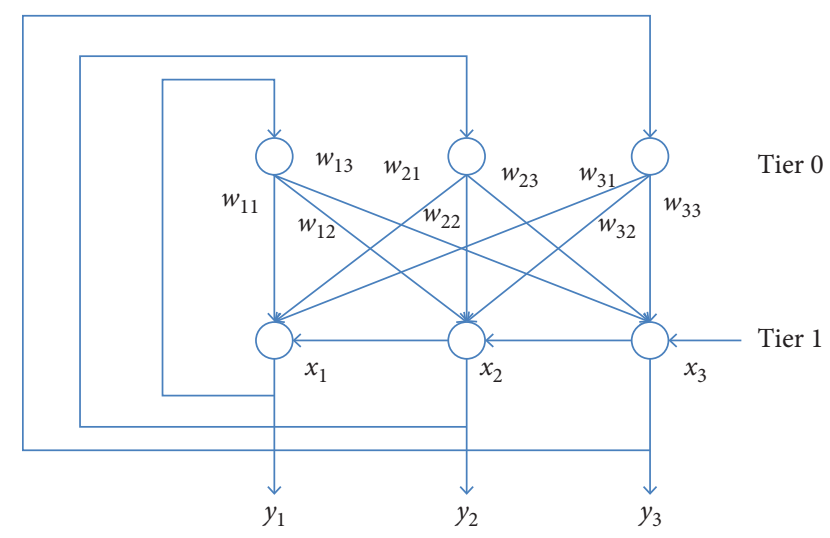

Figure 4: Discrete Hopfield network structure.
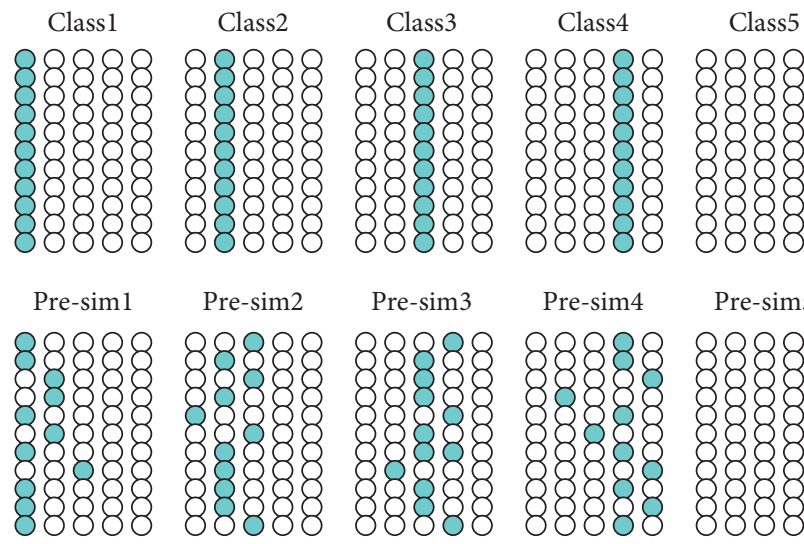

Pre-sim 4

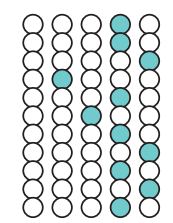

Pre-sim 5
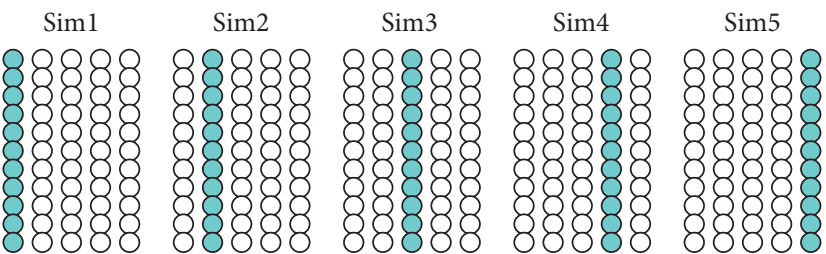

Figure 5: Simulation results of five national higher education evaluation index codes.

\section{Model Application and Evaluation of Policy Effects}

After the completion of the model and classification verification, we will choose one of the 20 countries to apply the model, put forward targeted policy reform suggestions, and apply the economic model to evaluate the implementation effect of reform policies in reality.

5.1. Select Model Application Object. First, we believe that countries with a score higher than 90 do not need to reform at present, because the higher education system in these countries is in a "very healthy" state. In addition, we believe that countries with a score below 45 do not have the social conditions for large-scale development of higher education, because these countries often invest too much in the military and economic fields, and the gap in social class differentiation is too large, which has brought resistance to the development of education.

For countries with a score of 75-90, we believe that the demand for reform in these countries is not strong. Because most of these countries have adopted higher education policies equivalent to those of the "first tier" countries and only because of the late start of higher education reform and the large population base, the improvement of higher education system lags behind and the score is lower.

At the same time, considering the universality of problem analysis, since South Korea, New Zealand, France, Sweden, and Brazil all have the characteristics of developed countries, and developed countries only account for $20 \%$ in the world. Therefore, in order to make the model more universal and realistic, we believe that applying the model and policy reforms to countries with poor ratings has more research value.

In the "poor" score of 45-60, India has a large population, caste system, and low enrollment rate, which makes it difficult to deepen the reform policy of higher education development. Therefore, we choose Vietnam with a smaller population and a higher enrollment rate to apply the model and put forward the reform policy.

5.2. Vietnam's Higher Education Reform and Policy Effects. We first collected data related to higher education in Vietnam from 2005 to 2020 , and secondly found that there are more vacancies. Because the autoregressive model can better describe the relationship between the current value and the historical value, it uses the historical data of the variable itself to predict itself, and the data have autocorrelation and meet the requirements of stability [22-25]. Therefore, we use the time series autoregressive model to complete a small amount of missing data, the formula is as follows:

$$
Y_{t}=\beta_{1} Y_{t-1}+\beta_{2} Y_{t-2}+\cdots+\beta_{p} Y_{t-p}+Z_{t},
$$

where $Y_{t}$ is the observed value of the prediction object, and $Z_{t}$ is the error. As the target of prediction, $Y_{t}$ is affected by changes in its own historical data.

After obtaining complete data, calculate the weights of 11 indicators of the Vietnamese higher education system, and use a heat map to show the development trend of the importance of each indicator, as shown in Figure 6 . According to the heat map, it can be found that with the passage of time, the infrastructure and teaching level of Vietnam's higher education development have been continuously improved, and the proportion of education equity and scientific research level to the score has gradually increased.

Therefore, in order to promote the development of higher education in Vietnam, we have designed a 30-year reform goal. We will elaborate on the following four aspects:

(i) Education infrastructure: the number of colleges and universities reaches 600 , and the number of college teachers reaches more than 180,000. 


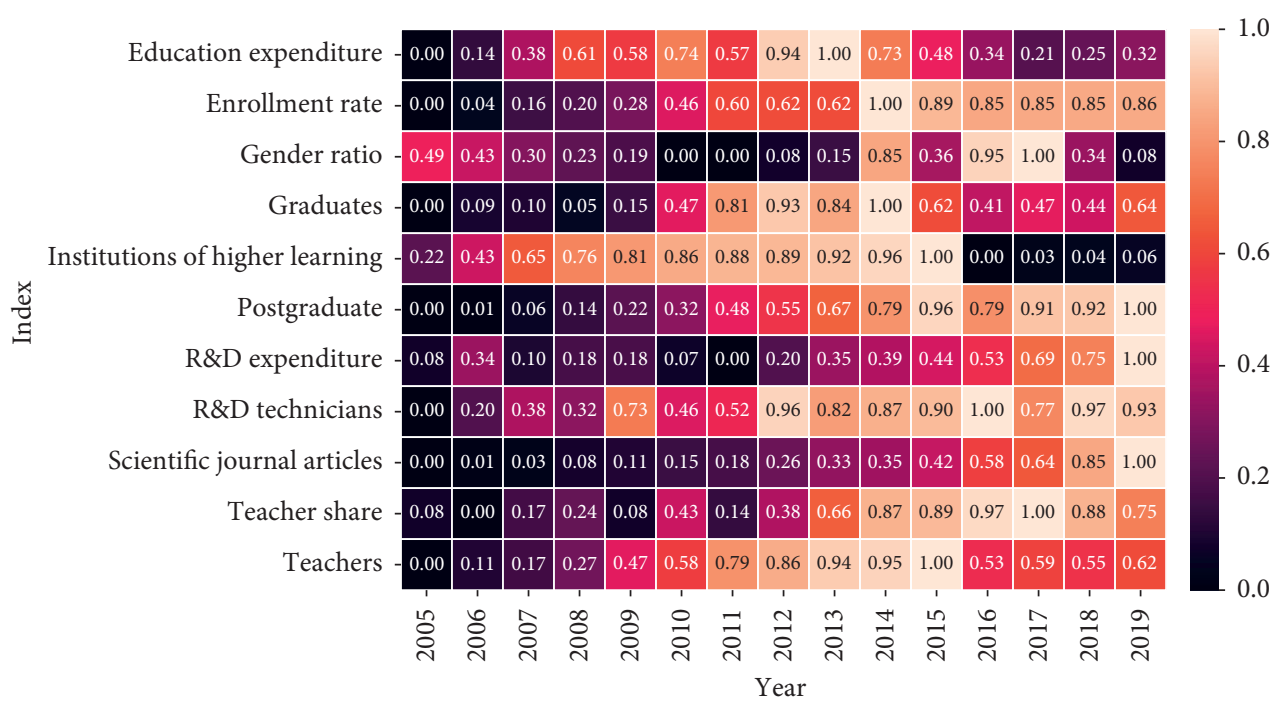

FIgURE 6: Vietnam higher education index heat map.

(ii) Educational equity: the gender ratio is close to $1: 1$, and the gap between public universities and private universities is continuously narrowing.

(iii) Teaching level: the number of graduates has reached 4 million, the further education rate has reached $15 \%$, and the education expenditure is no less than $4.5 \%$ of the government's financial expenditure.

(iv) Scientific research level: the number of articles in scientific journals reaches 6000 , and the number of technical talents reaches 800000 every year. The expenditure on scientific research accounts for $45 \%$ of the university's expenditure.

The establishment of a time series model can help us predict the growth of HECL between 2020 and 2050, but this does not reflect the impact of our policy recommendations. Therefore, a new growth model needs to be defined.

First, reintroduce the construction goal $V$. We assume that the progress of our policy construction goal is linear as time increases, so the progress $P$ represented by the goal completed at time $t$ is

$$
p_{i}=\frac{V_{i} t}{T}
$$

Then, we can calculate the overall average progress as $p$ :

$$
P=\frac{p_{i}}{\sum_{i=1}^{n} p_{i}}
$$

Among them, $T$ represents the final goal of the reform to be completed by 2050, and $i$ represents the 11 indicators in the model setting.

The average progress $P$ can represent the impact of our policy implementation to some extent, but it means that our policy will receive feedback immediately after implementation, which is contradictory to the real world, so we try to introduce it to describe the growth process:

$$
\frac{\mathrm{d} s}{\mathrm{~d} t}=\mathrm{PS} \frac{K-s}{K} .
$$

S-curve is the characteristic of logistic equation, which can well describe the objective law that marginal utility first increases and then decreases in the process of policy implementation. Therefore, we introduce the differential equation of logistic model which can describe population or population growth to analyze this problem. In this equation, the average progress $P$ is used to replace the population growth potential index of the original equation, the HECI score $s$ at time $t$ is used to replace the population number, and the HECL upper limit $K$ replaces the maximum capacity, which is 100 here.

In Figure 7, we can see that after the implementation of the target policy in 2020, there has been a slow growth period close to 20 years, which is the transition period. After the transition period, it will enter the final state. Under the influence of our policy, the final state, whether it is the growth rate or the HECI, completely exceeds the original estimated state, which proves the validity of the policy suggestions given above.

5.3. Cobweb Model: Realistic Dilemma-The Difficulty of Changing Reality. Even if the model proves at the theoretical level that the implementation of reforms has an obvious positive effect on the improvement of the higher education system, in reality, it often encounters other economic problems. The basic support for the reform is the state's continuous and long-term provision of large amounts of funds, but as a developing country, it is more difficult for Vietnam to meet this condition. If our policy is used to significantly increase the expenditure on higher education, it is likely to reduce the expenditure on other aspects, trigger a crisis in related industries, and ultimately reduce fiscal revenue. The reduction in education expenditure has further 


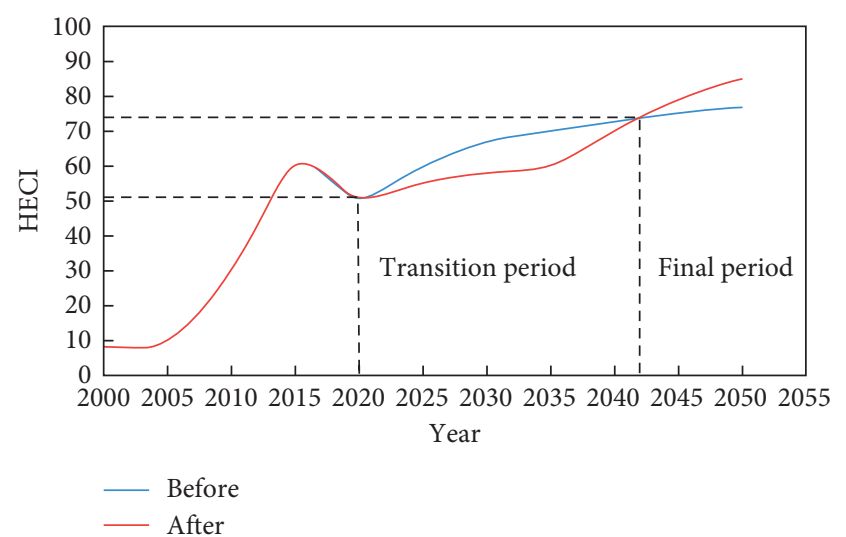

FIGURE 7: The effect of reforms in the transitional and final phases.

reduced the role of education expenditure. This phenomenon can be explained in conjunction with the cobweb model in economics.

The cobweb model is a dynamic analysis theory, which is used to explain the different fluctuations of some commodities with long production cycle when they lose equilibrium. At the same time, the cobweb model is a typical economic model with time lag effect, which has strong theoretical significance and practical value [26-30]. Based on this, we introduced the cobweb model into the evaluation of the future development of the Vietnamese higher education system. We use difference equations to construct a higher education supply and demand system. The supply side is national financial appropriation and the demand side is colleges and universities. Time is a discrete variable rather than a continuous variable, which is more in line with the dual meaning of mathematics and economy. The result can be effectively extended to the application of the country's higher education system reform in real life.

We make the following assumptions about the cobweb model for evaluating the effects of higher education reform policies: (1) the current demand for college education funds depends on the price of the current education cost; (2) the amount of financial appropriation for education funds in this period does not depend on the price of the current period of education costs but depends on the price of the previous period; (3) when the demand for education funds is the same as the state financial appropriation, equilibrium is reached.

According to the above assumptions, an equation system containing three equations can be obtained to represent the cobweb model:

$$
\left\{\begin{array}{l}
D=f(p) \\
S=g(p), \\
D=S .
\end{array}\right.
$$

We regard the amount of fiscal appropriation in period $t$ as determined by the demand in period $t-1$, and the expected price can be expressed as $P_{t-1}$. The supply and demand system in the form of difference equation can be expressed as

$$
\left\{\begin{array}{l}
D_{t}-D^{*}=b\left(P_{t}-P^{*}\right), \\
S_{t}-S^{*}=b_{1}\left(P_{t-1}-P^{*}\right), \\
D_{t}=S_{t}
\end{array}\right.
$$

Among them, $b<0, b_{1}<0$, respectively, represent the elasticity of demand and the elasticity of supply. Solving the equations, we can get

$$
P_{t}-P^{*}=\frac{b_{1}}{b}\left(P_{t-1}-P^{*}\right)
$$

According to the obtained first-order constant coefficient difference equation, there are

$$
\left\{\begin{array}{l}
P_{2}-P^{*}=\frac{b_{1}}{b}\left(P_{1}-P^{*}\right), \\
P_{3}-P^{*}=\frac{b_{1}}{b}\left(P_{2}-P^{*}\right), \\
\ldots \ldots \\
P_{t}-P^{*}=\frac{b_{1}}{b}\left(P_{t-1}-P^{*}\right) .
\end{array}\right.
$$
results:

We iterate the above $T-1$ equations and get the following

$$
P_{t}-P^{*}=\left(\frac{b_{1}}{b}\right)^{t-1}\left(P_{1}-P^{*}\right) .
$$

If $\left|b_{1} / b\right|<1, \lim _{t \rightarrow \infty} P_{t}=\lim _{t \rightarrow \infty}\left[\left(b_{1} / b\right)^{t-1}\left(P_{1}-P^{*}\right)\right.$ $\left.+P^{*}\right]=P^{*}$.

This shows that the funds of phase $t$ will fluctuate with the change of time, and the fluctuation range will gradually decrease and finally reach the equilibrium price $P^{*}$. At this time, the cobweb is in the form of convergence, as shown in Figure 8.

Due to the interference of some external factors, the development of higher education will be limited if the financial revenue as the supply side reduces the funding for higher education in the later period. Affected by the time lag effect, the development of higher education will gradually return to the state before the reform after the expected financial investment is not obtained for a long time.

If $\left|b_{1} / b\right|>1, \lim _{t \rightarrow \infty} P_{t}=\lim _{t \rightarrow \infty}\left[\left(b_{1} / b\right)^{t-1}\left(P_{1}-{ }^{*} P\right)\right.$ $\left.+P^{*}\right]=\infty$.

This shows that the funds of the $t$ period will fluctuate with the change of time, and the range of fluctuation will gradually increase, keep away from the equilibrium point $P^{*}$, and finally tend to $\infty$. At this time, the cobweb is divergent as shown in Figure 9.

If fiscal revenues continue to be allocated to higher education, higher education will continue to develop. However, for the economic development of Vietnam, due to the impact of the COVID-19 and the economic downturn, a large amount of financial supply to higher education for a long time is unrealistic in the short term. 


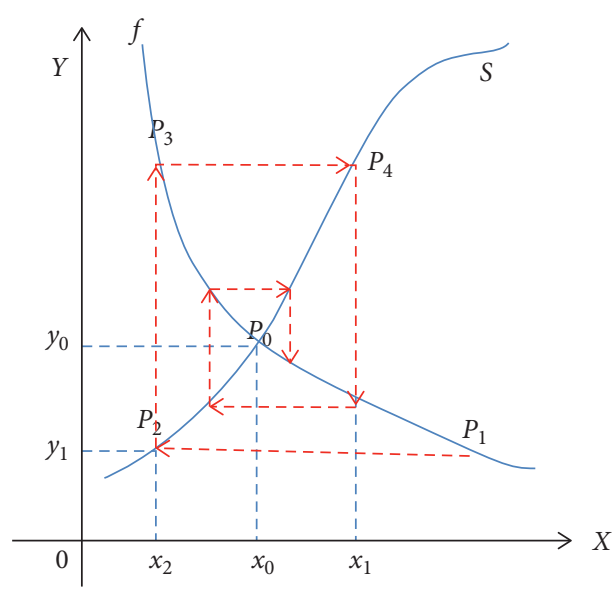

Figure 8: Convergent cobweb model.

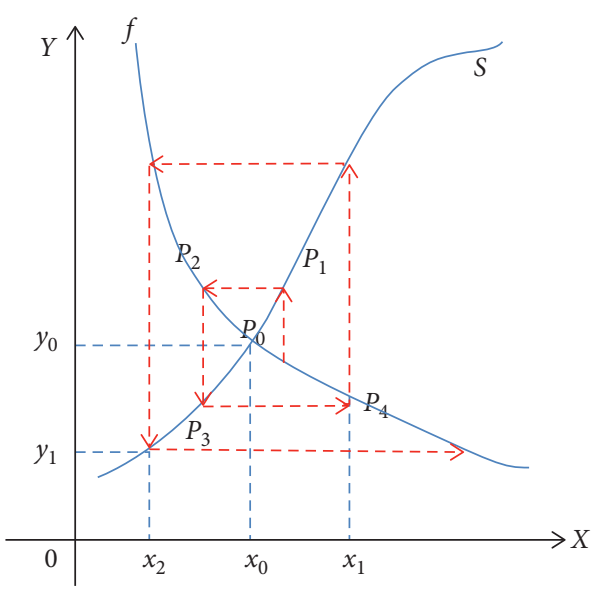

Figure 9: Divergent cobweb model.

To sum up, we think that the policy impact in the transition period and the final period is very significant, but the specific impact on the country and society depends on the size of $\left|b_{1} / b\right|$. However, the financial supply and demand elasticity of education policy will not be accurately calculated by using an over idealized model. Therefore, the uncertainty of specific parameters in the real world may cause the impact of our policy implementation, which is mainly realized as the convergence of the cobweb model.

In reality, the time lag effect often has different degrees of impact in many aspects. We will analyze it from five aspects: students, teachers, schools, communities, and countries.

For students, the government's investment in education, whether in the direct form of issuing funds or in indirect form such as improving the quality of education, will attract a large number of students to participate. However, due to the strong uncertainty in the form, strength, and scope of the policy, accidents will inevitably occur. For example, the payment of subsidies for poor students has stagnated, and such students often have to drop out of school and go home. Or the lack of facilities in colleges and universities has caused the quality of education to decline, and the quality of graduates is significantly lower than expected.
For teachers, the increase in salary will increase the enthusiasm for teaching and help the development of the higher education system. However, under the influence of tax tightening policy, such as the increase in personal income tax rates, when the actual increase in teacher income is far less than expected, the effect of the implementation of education policies will no longer be significant, which will exacerbate the unfairness of educational resources between regions.

For schools, it is necessary to keep increasing funds for employing high-tech talents, purchasing expensive imported experimental equipment, holding international forums and conferences, and other educational expenses for a long time, which will be directly affected by the fluctuation of educational funds allocation, so it is difficult to maintain the improvement of comprehensive strength of schools.

For the community, the transitional period of higher education construction plan can attract some young people to continue to complete their studies. Once the cobweb model effect appears, it means that some students will be forced to return to the community due to poverty and become unemployed in the case of economic downturn, which will undoubtedly aggravate the chaos of the community and increase the cost of community security.

For the country, the reduction of investment in higher education will have a huge impact on the country's high-tech industry research and development. Scientists and research institutes who lack scientific research funds will not be able to continue to study top technologies and translate theoretical results into reality for economic development. On the contrary, it is necessary to spend high prices to purchase patents or use rights in other countries, making the economy long-term labor-intensive, which has brought huge obstacles to future economic transformation.

In summary, even under the premise that our expected results are good, the turbulence brought about by this uncertainty to other aspects of society will not be accepted to a large extent, and it will be more difficult to change the real world.

\section{Conclusion}

In the article, we established a comprehensive system of higher education evaluation, calculated the weight and entropy of 11 indicators through TOPSIS and entropy weight method, and finally obtained the Higher Education Comprehensive Index (HECI). After that, we used the discrete Hopfield neural network to verify the accuracy of the classification and obtained the same classification results. In order to make the model more realistic and universal, we choose Vietnam as the research object and predict the changes before and after Vietnam's higher education policy through an autoregressive model. Taking into account the time lag effect of policy implementation, we used the cobweb model to estimate the implementation of the policy in reality, analyzed from the five perspectives of students, teachers, schools, community, and the country, and concluded that it is very difficult to change reality. 
The analysis of this paper also has shortcomings. In the use of the cobweb model, it may expand the impact of information asymmetry. The cobweb model is based on the fact that the supply side and the demand side are in the situation of information mismatch. However, Vietnam belongs to a socialist country, which is under the leadership of macrocontrol and centralized planning. The impact of this information asymmetry may not be as strong as our model considers.

The advancement of the research method in this paper is reflected in many aspects, such as data processing and visualization, the integration of interdisciplinary knowledge, and the evaluation of policy effects after model application. In the improvement of the model, we also use machine learning for verification after establishment to make the model stable. In the application of the model, we not only considered the application effect of the policy but also analyzed the reform resistance that may be encountered in reality through the economic model, so that the model has practical significance.

In conclusion, our models stand out due to its interdisciplinary approaches, innovation, cohesiveness, and high practical value. Our research results can provide a theoretical basis for evaluating the health of a country's higher education system and help education scholars reform higher education, thus promoting scientific research and economic development.

\section{Data Availability}

The data in this paper come from Question F of the 2021 American College Students Mathematical Modeling Competition and the statistics of the World Bank.

\section{Conflicts of Interest}

The authors declare that there are no conflicts of interest regarding the publication of this paper.

\section{Acknowledgments}

This study was funded by the Teaching and Research Fund Project of the Education Department of Anhui Province (2020jyxm0017; 2018jyxm1305), "First-Class Course" of Anhui University of Finance and Economics (acylkc202008), and the Teaching and Research Fund Project of the Anhui University of Finance and Economics (acjyyb2019109; acjyyb2020011).

\section{References}

[1] P. T. Ng, "The global war for talent: responses and challenges in the Singapore higher education system," Journal of Higher Education Policy and Management, vol. 35, no. 3, pp. 280-292, 2013.

[2] X. X. Pan, Y. Y. Xu, and Y. Zhao, "Regional differences, spatial effects and influencing factors of my country's higher education development," Educational Academic Monthly, vol. 11, pp. 9-18, 2020.
[3] X. P. Dong and Q. H. Shi, "Modernization of China's higher education evaluation system: history, challenges and prospects," Journal of Southwest University (Social Science Edition), vol. 47, no. 1, pp. 104-227, 2021.

[4] T. Q. Ma and X. Wu, "Practical characteristics and development trend of higher education evaluation system in western countries," Journal of Beijing University of Science and Technology (Social Science Edition), vol. 26, no. 4, pp. 25-30, 2010.

[5] C. A. Pereira, J. Araujo, and M. de Lourdes Machado-Taylor, "The Brazilian higher education evaluation model: SINAES sui generis?" International Journal of Educational Development, vol. 61, no. 7, pp. 5-15, 2018.

[6] R. Tippelt, B. Schmidt, and A. V. Hippel, "Higher education evaluation in Germany," Research in Comparative and International Education, vol. 5, no. 1, p. 98, 2010.

[7] H. R. Kells, "Higher education evaluation systems for Latin America: an analysis of recent experiences and the formulation of a generalized model," Higher Education Policy, vol. 9, no. 3, pp. 239-253, 1996.

[8] B. Quinn, "Reformation or transformation? policy reform in Ireland's higher education system," Higher Education Policy, vol. 33, no. 6, pp. 159-177, 2020.

[9] B. R. Xu, "Research on the evaluation system of higher education service quality-based on the SERVPERF model," Journal of Nanjing Institute of Technology (Social Science Edition), vol. 17, no. 2, pp. 65-72, 2017.

[10] W. J. Ke and J. Wang, "Evaluation of urban higher education resources carrying capacity based on Entropy TOPSIS Model," Statistics and Decision, vol. 36, no. 18, pp. 50-53, 2020.

[11] R. Lumino and D. Gambardella, "Re-framing accountability and learning through evaluation: insights from the Italian higher education evaluation system," Evaluation, vol. 26, no. 2, pp. 147-165, 2020.

[12] Z. Zhang, B. Y. Ye, and G. Y. Ding, "Evaluation of the coordinated development of China's provincial higher education development level and economic and social competitiveness-based on the coordination degree model of minimizing dispersion coefficient," Journal of Hubei University of Economics, vol. 18, no. 6, pp. 32-41, 2020.

[13] I. Franco, O. Saito, P. Vaughter et al., "Higher education for sustainable development: actioning the global goals in policy," Curriculum and Practice, vol. 14, no. 6, pp. 1621-1642, 2020.

[14] H. Liu, Y. Yu, and W. S. Jiang, "Blockchain technology, differences in educational resources and high quality economic development: an empirical analysis based on the allocation of higher education resources in China," Journal of Shaanxi Normal University (Philosophy and Social Sciences Edition), vol. 49, no. 1, pp. 145-158, 2020.

[15] Z. Q. Wang, Y. Wang, and X. Y. Sun, "Study on the measurement of the competitiveness of higher education and related factors in countries along the belt and road," Journal of Southwest University (Social Science Edition), vol. 47, no. 1, pp. 112-227, 2021.

[16] Y. Liu and N. Li, "Research and judgement on the evaluation index system of higher education internationalization-based on the comparison of 9 evaluation index systems," Heilongjiang Higher Education Research, vol. 38, no. 8, pp. 77-83, 2020.

[17] L. Ge and Z. Y. Liu, "Research on the evaluation index system of university entrepreneurship education ability based on CIPP," Journal of Northeast University (Social Science Edition), vol. 16, no. 4, pp. 377-382, 2014. 
[18] X. H. Dang and Q. H. Li, "Evaluation of innovation and development ability of Shaanxi national high tech zone based on entropy weight improved TOPSIS," Science and Technology Management Research, vol. 37, no. 3, pp. 75-83, 2017.

[19] W. S. Wu and M. Fan, "Research on regional innovation capability evaluation and spatial distribution of each city in Anhui province based on entropy TOPSIS method," Journal of Changchun University of Science and Technology (Social Science Edition), vol. 32, no. 2, pp. 82-87, 2019.

[20] H. T. Zhang, X. R. Li, and T. Kong, "The application of BP neural network in missing data estimation," Computer Engineering and Design, vol. 14, pp. 3457-3459, 2007.

[21] S. L. Yin, J. Liu, and L. Teng, "A sequential cipher algorithm based on feedback discrete hopfield neural network and logistic chaotic sequence," International Journal of Network Security, vol. 22, no. 5, pp. 869-873, 2020.

[22] H. Xu, F. Ding, M. Gan, and E. Yang, "Two-stage recursive identification algorithms for a class of nonlinear time series models with colored noise," International Journal of Robust and Nonlinear Control, vol. 30, no. 17, pp. 7766-7782, 2020.

[23] Z. W. Liu and F. K. Zhu, "A new extension of thinning-based integer-valued autoregressive models for count data," Entropy, vol. 22, no. 1, p. 62, 2020.

[24] C. X. Xie and F. X. Wang, "GDP forecast based on ARIMADGM-BP combined model in Kashgar area," Mathematical Practice and Knowledge, vol. 50, no. 15, pp. 43-48, 2020.

[25] M. Q. Zheng and J. M. Zhu, "Forecast and analysis of Zhejiang province GDP based on ARIMA model," Natural Science Journal of Harbin Normal University, vol. 36, no. 3, pp. 56-61, 2020.

[26] J. Ren and X. D. Ma, "Research on cobweb models and stability of different expectations in the form of difference equations-taking the Chinese pork market as an example," Contemporary Financial Research, vol. 5, pp. 96-104, 2020.

[27] A. Naimzada, N. Pecora, and F. Tramontana, "A cobweb model with elements from prospect theory," Journal of Evolutionary Economics, vol. 29, no. 2, pp. 763-778, 2019.

[28] M. I. Chaudhry and M. J. Miranda, "Complex price dynamics in vertically linked cobweb markets," Economic Modelling, vol. 72, pp. 363-378, 2018.

[29] G. Xiong, J. Zhang, D. Shi, and X. Yuan, “Application of supply-demand-based optimization for parameter extraction of solar photovoltaic models," Complexity, vol. 2019, Article ID 3923691, 22 pages, 2019.

[30] D. B. Gao, "Research on cobweb economic model with type II functional response," Mathematics in Practice and Knowledge, vol. 50, no. 15, pp. 133-142, 2020. 